\title{
Novel Direct Synthesis of Mesoporous Tin Dioxide Network Intact up to $500^{\circ} \mathrm{C}$
}

\author{
Tariq Aqeel ${ }^{* 1}$, Heather F. Greer ${ }^{2}$, Wuzong Zhou ${ }^{2}$, Duncan W. Bruce ${ }^{3}$, Ali Bumajdad ${ }^{4}$ \\ 1 \\ Science Department, College of Basic Studies, the Public Authority of Applied Education and Training \\ (PAAET) P.O Box 23167, zip code Safat 13092, Kuwait. tm.aqeel@paaet.edu.kw \\ 2 School of Chemistry, University of St Andrews, St Andrews, KY16 9ST UK. \\ 3 Department of Chemistry, University of York, Heslington, YORK YO10 5DD, UK. \\ Chemistry Department, Faculty of Science, Kuwait University, P.O.Box 5969 safat 13060, Kuwait.
}

\begin{abstract}
We present a direct soft templating method to synthesise mesoporous tin dioxide network that maintains a porous structure after calcination at $400^{\circ} \mathrm{C}$ and $500{ }^{\circ} \mathrm{C}$ and has a relatively high BET surface area of 220 and $100 \mathrm{~m}^{2} \mathrm{~g}^{-1}$, respectively. TEM, BET and XRD results confirm that both crystal and pore sizes increase as a result of increasing the temperatures during the calcination step. This method is highly reproducible.
\end{abstract}

Key words:

Mesoporous tin dioxide, TEM, BET, XRD, XPS, pore and crystal sizes, calcinations.

\section{Introduction}

Tin dioxide is an $n$-type semiconductor having a band gap energy around $3.6 \mathrm{eV}[1]$ and can be used in various applications such as gas sensing, [2-5] as an electrode in galvanic or electrolyte cells, $[6,7]$ transparent electrode in solar cell and photocatalysis. [8-9] As a solid it forms a powder having a surface area in the range of $10-30 \mathrm{~m}^{2} \mathrm{~g}^{-1}$ and this low surface area limits its applicability as a sensor or electrode. Introducing porosity into its structure will increase the surface area and pore volumes significantly. Thus, many publications report the production of mesoporous tin dioxide, but they often been supported by substrates [10-13], sometimes lack reproducibility [14-15] or the product was supported by soft [16] or hard templates which were not removed completely. [14-15] We have recently tried to reproduce some of the published methods to synthesise mesoporous tin dioxide powders (free of the supporting substrate or the templating materials) using their procedures, but in our hands the methods were not reproducible, [14-15] for example, using hard templating materials such as mesoporous silica [14-15]. Here we found that under all conditions that we employed, the product always contained between 5 and $15 \%$ residual mesoporous silica which may in fact be a significant source of the high surface area $\left(100 \mathrm{~m}^{2} \mathrm{~g}^{-1}\right)$ claimed for the materials. [14-15] Other 
methods, for example using a soft templating support, [17], led to pore structure collapse after calcination at $400{ }^{\circ} \mathrm{C}$, giving a non-porous powder. However, based on our experience, we can manipulate this latter method to produce mesoporous tin dioxide powders free of the templating materials at elevated temperatures.

Based on a previous method, [17] we developed a methodology that gave mesoporous tin dioxide after calcination at $400{ }^{\circ} \mathrm{C}$ and $500{ }^{\circ} \mathrm{C}$. Moreover our product could withstand multiple heat treatments without losing this porosity, providing a good basis for the subsequent, post-synthetic introduction of nano-clusters into the pores or doping of the walls with other elements to modify chemical and physical properties. The method employed is highly reproducible.

\section{Results and Discussion}

\section{Synthesis}

Previous reports mixed the reagents without stirring for two days before removing the surfactant (tetradecylamine) by heating the product in ethanol under reflux for two hours (to remove the template) before calcining. This resulted in formally microporous materials, pore diameters of $14 \AA$ and $18 \AA$ arising from calcination temperatures of 300 and $350{ }^{\circ} \mathrm{C}$, respectively. The present methodology used slow stirring (around 100 r.p.m.) and increased the reaction time to three days to ensure good mixing and to produce thicker walls and then the surfactant (hexadecylamine) was removed using Soxhlet extraction with ethanol for 16-20 hours. This led to materials with an average pore diameter of $20 \AA$ and $22 \AA$ following calcination at $300^{\circ} \mathrm{C}$ or $400^{\circ} \mathrm{C}$, respectively.

\section{X-ray Diffraction}

Figure 1 represents the small-angle diffraction pattern for mesoporous $\mathrm{SnO}_{2}$ calcined at different temperatures. The small-angle reflection indicates that all have some structured porosity and, while this appears best defined at $400{ }^{\circ} \mathrm{C}$, it evidently extends to the sample treated at $500{ }^{\circ} \mathrm{C}$. Moreover, the fact that the $d$-spacing increases with calcination temperature $\left(49 \AA, 77 \AA\right.$ and $98 \AA$ at $300{ }^{\circ} \mathrm{C}$, $400{ }^{\circ} \mathrm{C}$ and $500{ }^{\circ} \mathrm{C}$, respectively) suggests that the structure is changing by having thicker walls and/or larger pore sizes. 


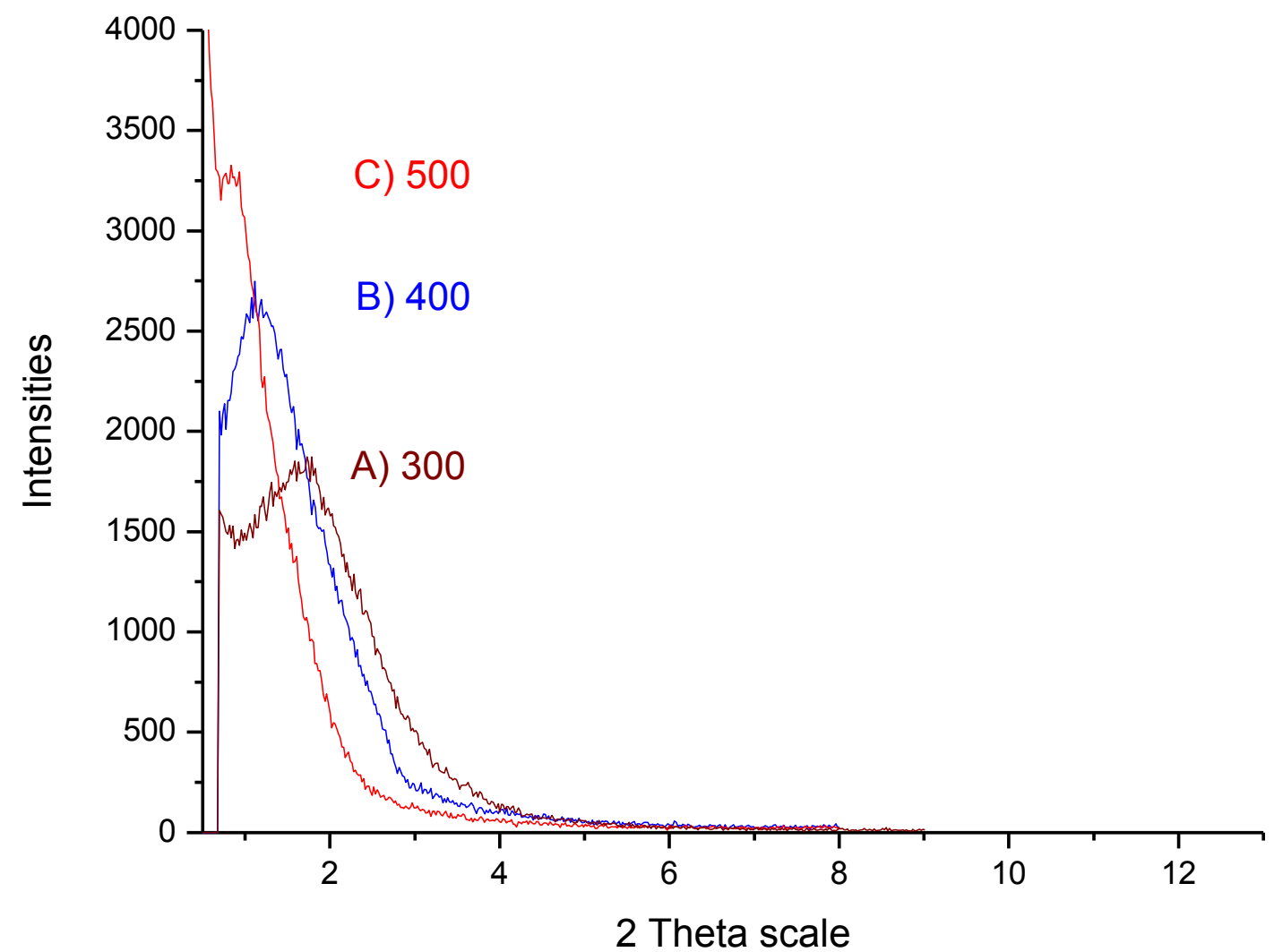

Fig.1 Small-angle XRD diffraction patterns for mesoporous $\mathrm{SnO}_{2}$ calcined at:

A) $300^{\circ} \mathrm{C}$, B) $400{ }^{\circ} \mathrm{C}$ and C) $500^{\circ} \mathrm{C}$

The wide-angle diffraction patterns (Fig. 2) confirm that all samples are crystalline and the structure is assigned as Cassiterite by comparison with library data. ${ }^{1}$ Moreover the wide-angle data show that the crystallinity is improving as the temperature increases by having sharper and narrower peaks which are more pronounced at $400^{\circ} \mathrm{C}$ and $500^{\circ} \mathrm{C}$ than at $300{ }^{\circ} \mathrm{C}$. Furthermore the crystal size increased as a result of the increase in the calcination temperature as evaluated using the Scherrer equation for the $<110>$ reflection, so that the average crystal sizes are calculated to be: $34 \AA$ at 300 ${ }^{\circ} \mathrm{C}, 52 \AA$ at $400{ }^{\circ} \mathrm{C}$ and $72 \AA$ at $500{ }^{\circ} \mathrm{C}$. Many other papers also reported the increase in particle size as a direct result of increasing the temperature. [18-20]

\footnotetext{
${ }^{1}$ EVA software associated with $D 8$ advanced diffractometer DIFFRAC ${ }^{\text {plus }}$ XRD instrument.
} 


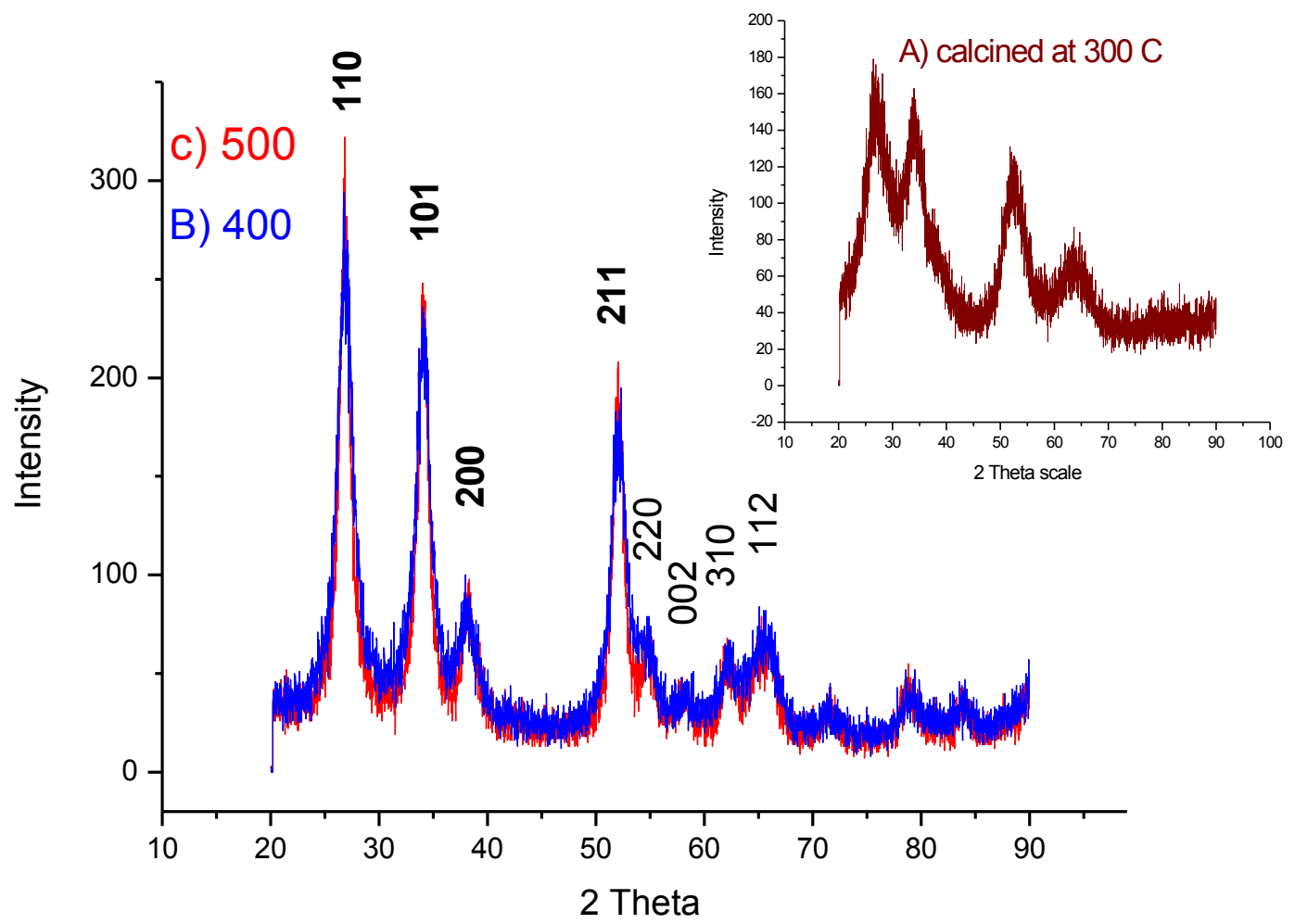

Figure 2 The wide-angle XRD patterns for samples A, B and C calcined at the indicated temperatures.

\section{BET results}

Brunauer-Emmett-Teller (BET) $\mathrm{N}_{2}$ sorption measurements were performed to study the removal methods of the templating materials and the effect on the product. The removal of the templating materials was performed either by heat treatment alone or by Soxhlet extraction using ethanol followed by heat treatment which reveals the following results. 


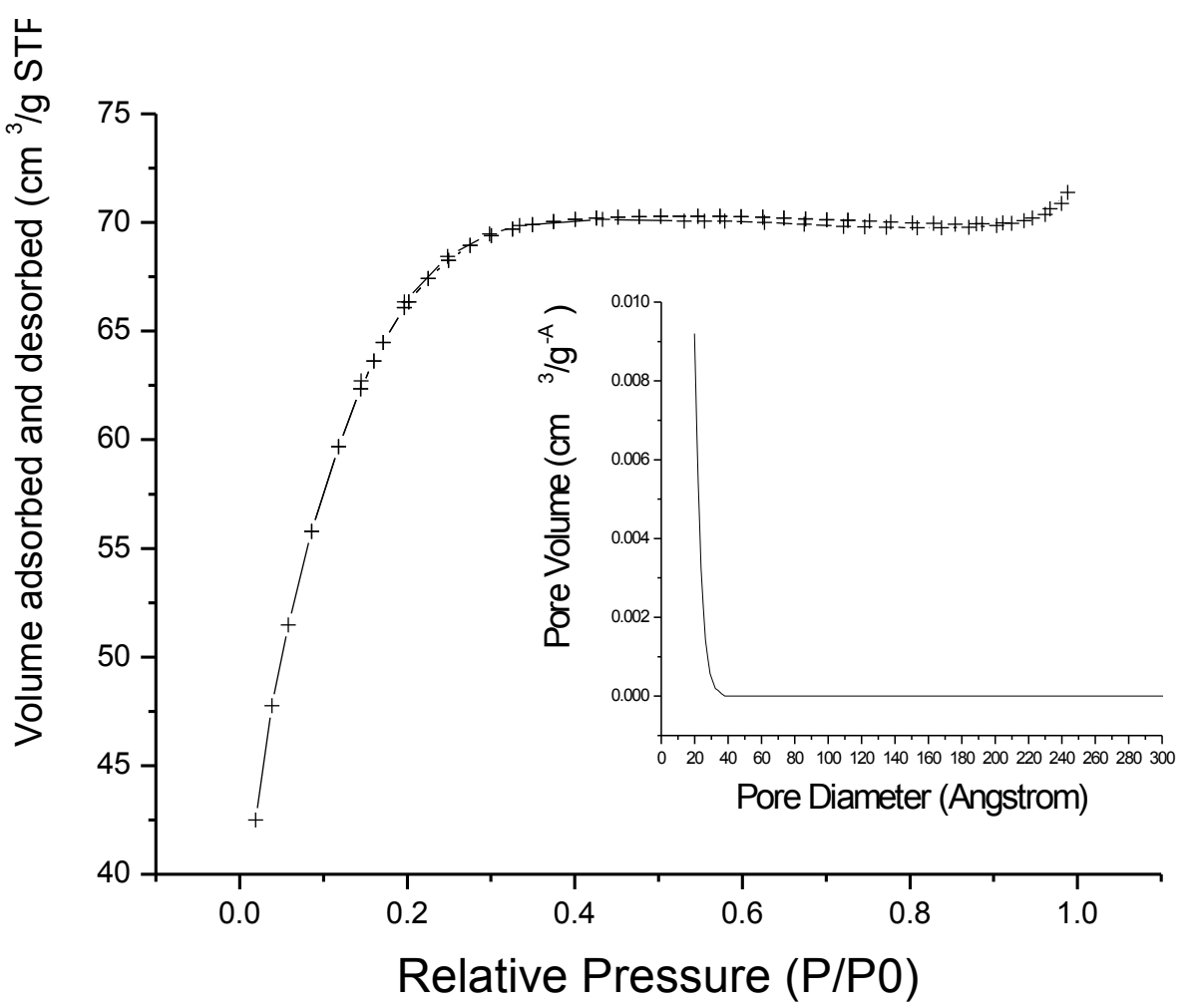

(a)

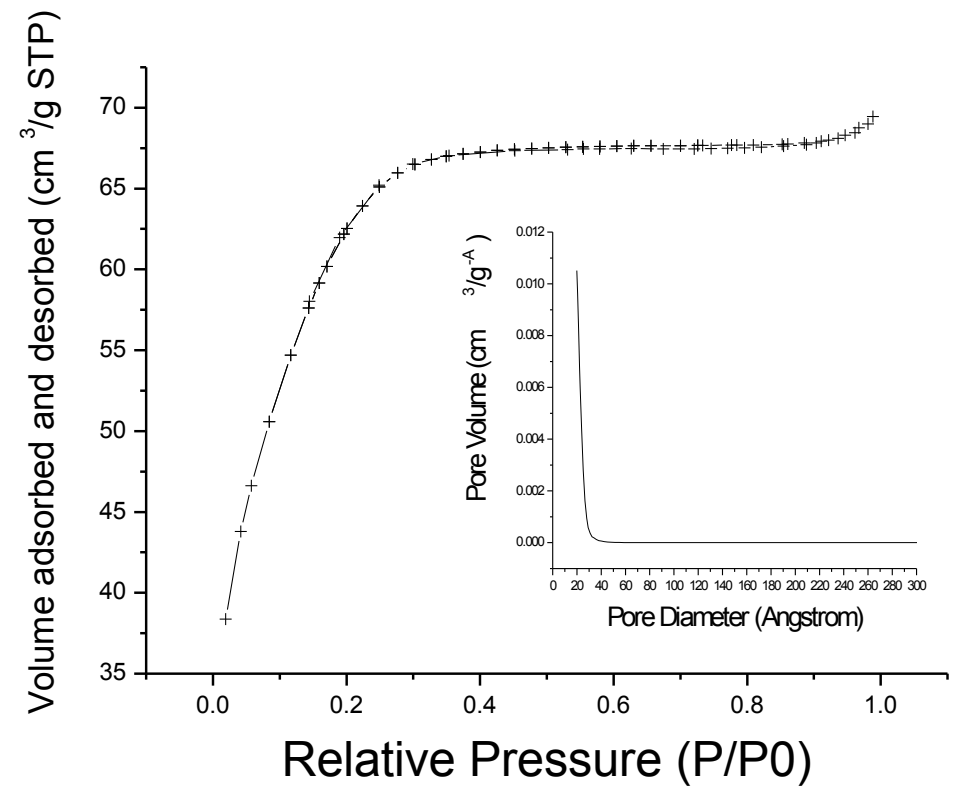

(b)

Figure 3 The isotherm for porous tin dioxide (a) calcined at $300{ }^{\circ} \mathrm{C}$ and (b) Soxhlet extracted for $16-20 \mathrm{~h}$ then calcined at $300^{\circ} \mathrm{C}$. 
For heat treatment at $300{ }^{\circ} \mathrm{C}$, one batch was divided into two samples and the removal of the templating material of the as-synthesised product was performed differently. The first sample was washed in water, rinsed with ethanol then calcined at $300{ }^{\circ} \mathrm{C}$ for 2 hours (Fig. 3a), whereas the other was treated in a Soxhlet ethanol extraction for $16-20$ hours then calcined at $300{ }^{\circ} \mathrm{C}$ for 2 hours (Fig. $3 b$ ). Both samples showed similar isotherms (Type I which indicates microporosity of pore size $<2$ $\mathrm{nm}$ ) and BET results show pore volumes of $0.1 \mathrm{~cm}^{3} \mathrm{~g}^{-1}$, BET surface areas of $230 \mathrm{~m}^{2} \mathrm{~g}^{-1}$ and uniform pores in the $20 \AA$ range, which fall in the borderline between micro- and meso-porosity according to IUPAC classification. [21]

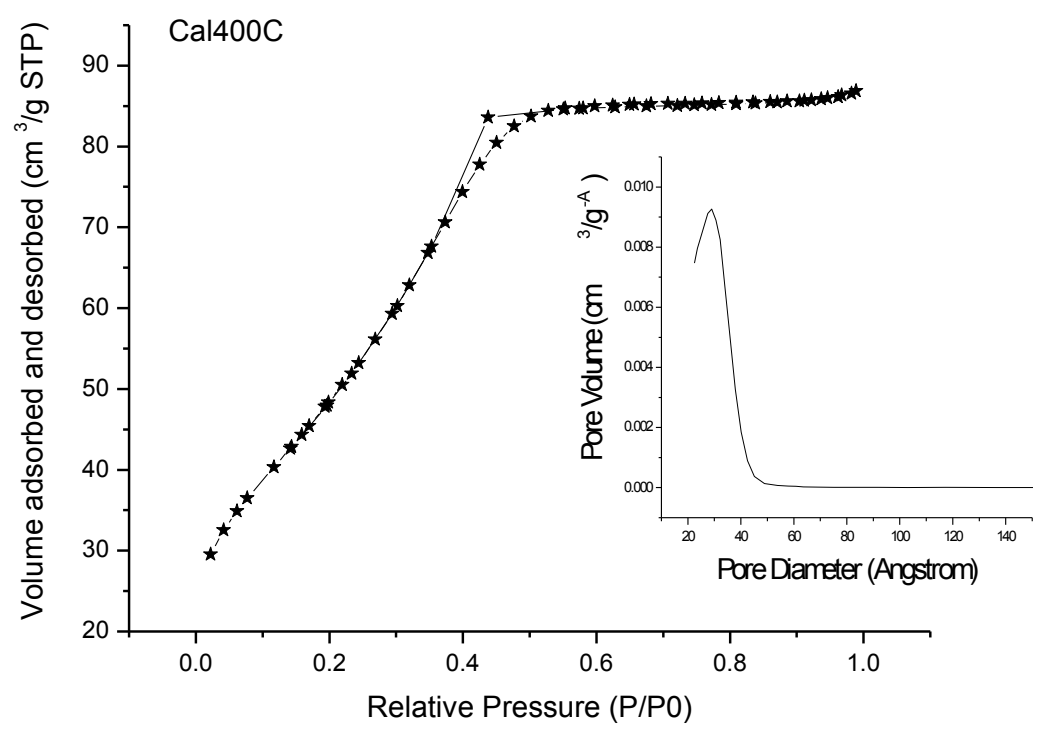

(a)

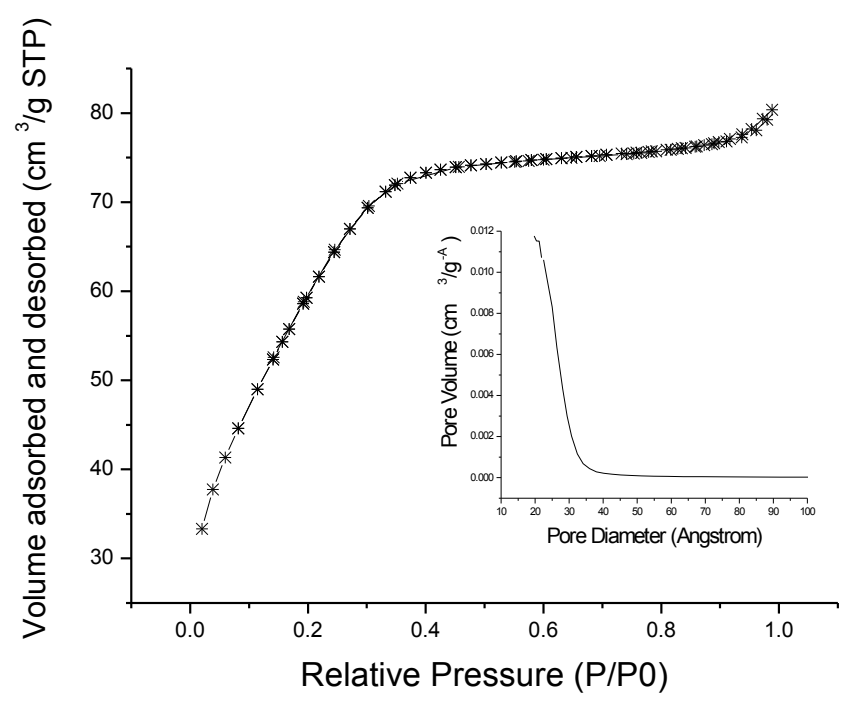

(b)

Figure 4 The isotherm for tin dioxide (a) calcined at $400{ }^{\circ} \mathrm{C}$;

(b) Soxhlet treated then calcined at $400^{\circ} \mathrm{C}$. 
Two further batches were treated similarly, only this time the calcination temperature was $400{ }^{\circ} \mathrm{C}$. Thus while the sample that was subjected to Soxhlet extraction followed by calcination again showed a Type I isotherm, the sample that was simply calcined showed some evidence of hysteresis suggesting a possible Type IV isotherm (hysteresis loop type $\mathrm{H} 2$ ) and mesoporosity. Indeed, the pore size for the calcined sample averaged a diameter of $29 \AA$ with a surface area of $179 \mathrm{~m}^{2} \mathrm{~g}^{-1}$. When extracted and then calcined, the pore diameter reduced to $22 \AA$, there was no hysteresis loop and the surface area was $221 \mathrm{~m}^{2} \mathrm{~g}^{-1}$.

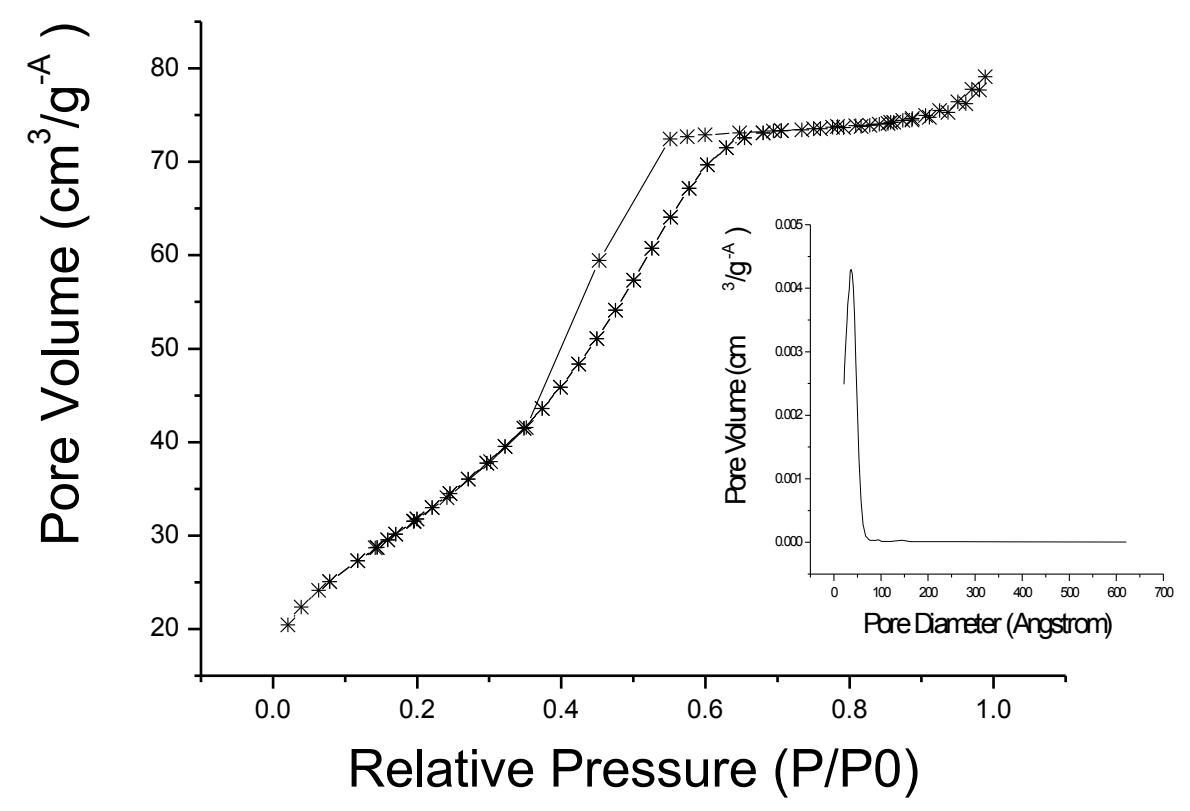

Figure 5 The isotherm for mesoporous tin dioxide Soxhlet treated then calcined at $500{ }^{\circ} \mathrm{C}$

For heat treatment at $500{ }^{\circ} \mathrm{C}$, we know that the crystal size of tin dioxide will increase directly with the heat reducing the size of the pores. [18]. We therefore decided to use Soxhlet extraction with ethanol for 16-20 hours for template removal before calcining hoping to maintain the porous structure intact. Thus, we calcined at $300{ }^{\circ} \mathrm{C}$ for 30 minutes, at $400{ }^{\circ} \mathrm{C}$ for a further 15 minutes (ramp rate $=2{ }^{\circ} \mathrm{C} \mathrm{min}^{-1}$ ) and then at $500{ }^{\circ} \mathrm{C}$ for 10 minutes $\left(\right.$ ramp rate $=3^{\circ} \mathrm{C} \mathrm{min}{ }^{-1}$ ). Best results gave a BET surface area of $116 \mathrm{~m}^{2} \mathrm{~g}^{-1}$, a pore volume of $0.12 \mathrm{~cm}^{3} \mathrm{~g}^{-1}$ and an average pore diameter of 56 $\AA$. The hysteresis loop (falling between the $\mathrm{H} 1$ and H2 IUPAC classification) of the desorption cycle was more pronounced indicating larger pore size distribution ranging from 26 - 66 A as presented in Fig. 5. Class $\mathrm{H} 1$ hysteresis is defined as arising from cylindrical pores whereas $\mathrm{H} 2$ type hysteresis represents an interconnecting pore system or irregular shape pores [21]; our TEM results are consistent with both. Other samples similarly prepared had comparable results with average BET surface area around $100 \mathrm{~m}^{2} \mathrm{~g}^{-1}$. 
The heat treatment of the samples produced larger pore sizes, ranging from 20 to $60 \AA$ as a result of the calcinations temperature increment. These results observed by BET data agree with the increase in the $d$-spacing value calculated from the XRD spectrum (Fig. 1).

\section{TEM results}

The low-magnification TEM image (Fig. 6a) of the $\mathrm{SnO}_{2}$ sample calcined at $400{ }^{\circ} \mathrm{C}$ shows a network of spherical-like particles ( $c a 300-500 \mathrm{~nm}$ ). The high porosity of these spherical particles can easily be identified in higher-magnification images (Fig. 6b). HRTEM confirmed that the spherical particles were built up of nanocrystallites with a dimension of 4-5 nm (Fig. 6c). The marked lattice fringes in Fig. $6 \mathrm{c}$ with $d$-spacings close to $3.34 \AA$ match to the (110) plane of $\mathrm{SnO}_{2}$ (cassiterite). The pores are actually the space in between the nanocrystallites and are, therefore, irregularly shaped and disordered due to the non-uniform arrangement of nanocrystallites. High intensities of $\mathrm{Sn}$ and $\mathrm{O}$ in the EDX spectrum (inset of Fig. 6c) further supports identification of the $\mathrm{SnO}_{2}$ phase and confirm its purity. The $\mathrm{Cu}$ in this spectrum is from the copper grid on which the specimen was deposited. 

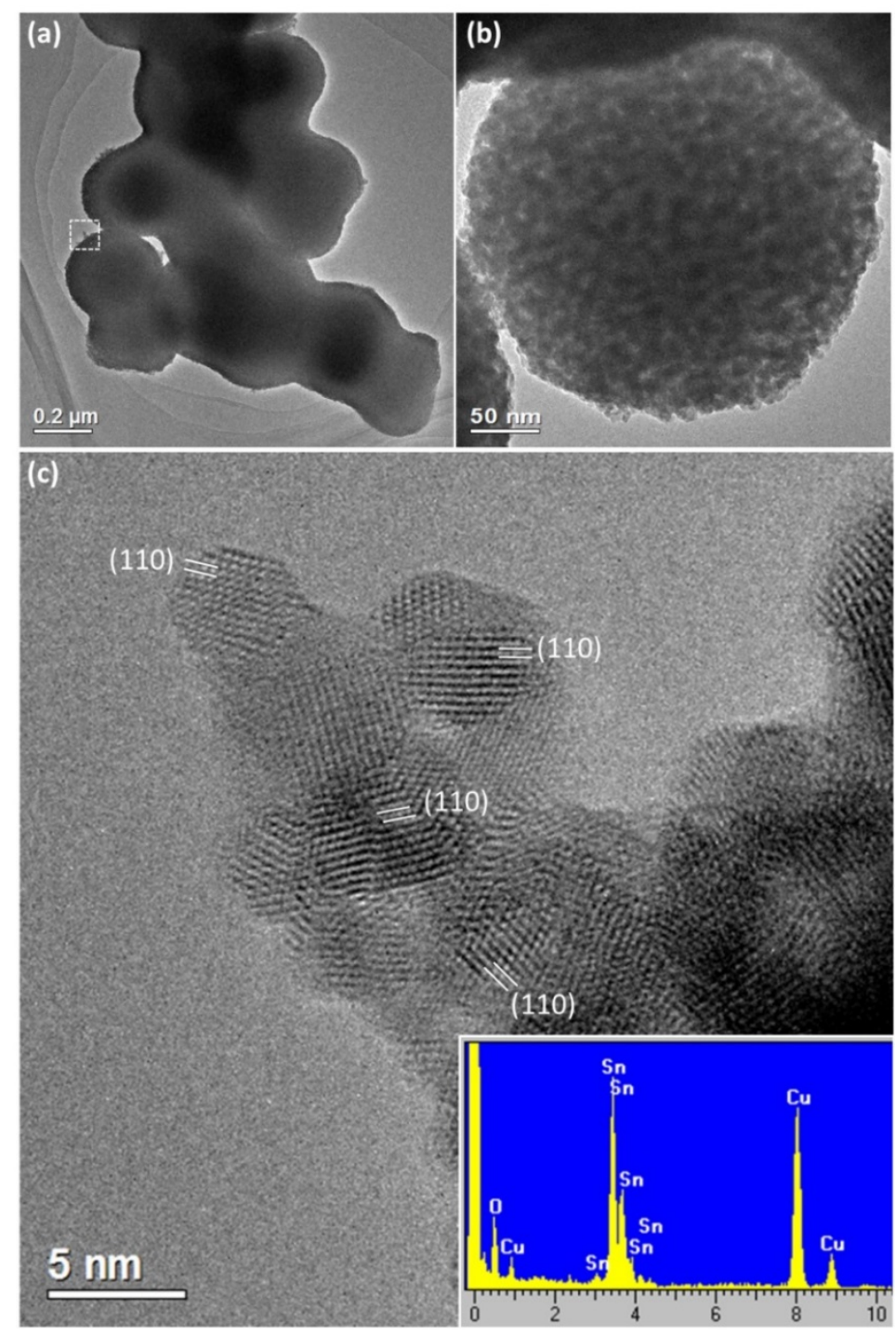

Figure 6 TEM images of mesoporous $\mathrm{SnO}_{2}$ calcined at $400{ }^{\circ} \mathrm{C}$ : (a) Low-magnification TEM image showing spherical particles with a network-like arrangement; (b) TEM image showing the spherical particles have a porous structure consisting of nanocrystallites; (c) HRTEM image recorded from the area marked in (a). The $d$-spacings measured from many nanoparticles corresponds to the (110) plane of $\mathrm{SnO}_{2}$. A typical EDX spectrum of this specimen is shown in the inset.

Similarly, low-magnification TEM images (Fig. 7a) of the $\mathrm{SnO}_{2}$ specimen calcined at $500{ }^{\circ} \mathrm{C}$ also show a network structure but with a smaller size, e.g. 200-250 nm, of spherical building units. Many nanocrystallites could also be observed at slightly higher magnifications (Fig. 7b). The visibility of many pale contrasted voids in low-magnification TEM images of the specimen calcined at $500{ }^{\circ} \mathrm{C}$ (Fig. $7 \mathrm{a}$ ), but not $400^{\circ} \mathrm{C}$ (Fig. 6a), is consistent with the average pore size data. The HRTEM image in Fig. $7 \mathrm{c}$ confirmed that the nanocrystallite size is $6-9 \mathrm{~nm}$, which matches with that obtained from Scherrer calculations. It is noted that the nanocrystallites in the specimen calcined at $500{ }^{\circ} \mathrm{C}$ are larger and have defined facets; the majority are (110), whereas the smaller crystallites in the $400{ }^{\circ} \mathrm{C}$ sample are spherical and without obvious facets. All marked lattice fringes in Fig. $7 \mathrm{c}$ correspond to 
the (110) plane of $\mathrm{SnO}_{2}$ with a $d$-spacing close to $3.34 \AA$. A typical EDX spectrum of the specimen calcined at $500^{\circ} \mathrm{C}$, displaying only high intensities of $\mathrm{Sn}$ and $\mathrm{O}$, is shown in the inset of Fig 7c. Despite the disordered arrangement of nanocrystallites in both the $400^{\circ} \mathrm{C}$ and $500{ }^{\circ} \mathrm{C}$ specimens, the connection between the nanocrystallites are evidently relatively strong otherwise a network structure would not be possible.

Based on the TEM results the porous structure is similar to single crystalline metal oxides produced using mesoporous silicas as hard templates [22], although the pores in $\mathrm{SnO}_{2}$ are irregular and the wall is polycrystalline rather than single crystalline. The network structure also indicates that the formation of these materials is not resulted from aggregation of pre-formed nanocrystallites. The precursor molecules/ions aggregate into some amorphous spherical particles first, followed by multiple nucleation and development of nanocrystallites in the particles simultaneously. Consequently, the connection of the nanocrystallites is chemical rather than physical. A comparable mesostructured is the so-called walnut-like perovskite [23]. 

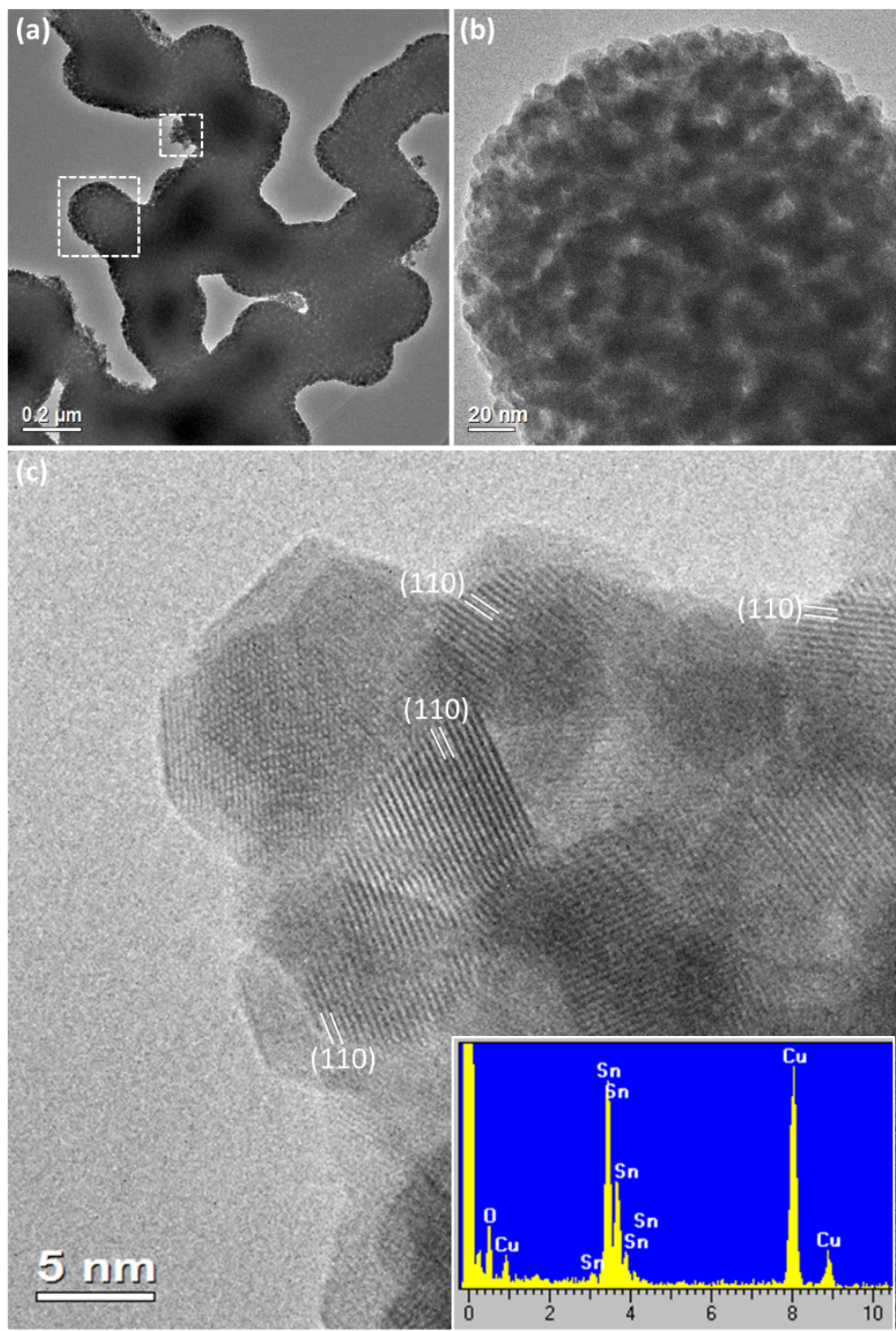

Fig. 7 TEM images of mesoporous $\mathrm{SnO}_{2}$ calcined at $500{ }^{\circ} \mathrm{C}$ : (a) Low-magnification TEM image showing a network type structure; (b) higher-magnification TEM image recorded from the area marked by a large box in (a) - a highly porous structure consisting of nanocrystallites can be identified; (c) HRTEM image recorded from the smaller marked region in (a) - the marked lattice fringes have $d$-spacings that correspond to the (110) plane of $\mathrm{SnO}_{2}$. The inset shows a typical EDX spectrum recorded from this specimen. 


\section{XPS results}

The X-ray Photoelectron Spectrometry (XPS) data, presented in Figure 8 and Table 1, reveal that the total carbon content is $1.56 \%$ for the sample calcined at $500{ }^{\circ} \mathrm{C}$ and $1.88 \%$ for the sample calcined at $400{ }^{\circ} \mathrm{C}$. Subtracting 1.21 and 1.25 atom\% from the total carbon as being adventitious, for the samples calcined at 500 and $400^{\circ} \mathrm{C}$, respectively, the resultant levels are 0.35 and 0.63 atom\% $\mathrm{C}$ for the samples calcined at $500{ }^{\circ} \mathrm{C}$ and $400{ }^{\circ} \mathrm{C}$, respectively. This arises from residual carbon from the starting template and is lower for the higher calcination temperature. [24] Detected surface nitrogen atoms are from the starting templating material and the content was $0.2 \%$ for the sample calcined at $400{ }^{\circ} \mathrm{C}$ and $0.1 \%$ for that calcined at $500^{\circ} \mathrm{C}$. Both the carbon and the nitrogen results confirm the removal of the templating materials and show that the mesoporous tin dioxide structure exists intact without the support of the carbon templates. Moreover $50.0 \%$ of $\mathrm{Sn}$ atoms exist in the framework as tin dioxide as represented by $\mathrm{Sn} 3 \mathrm{~d} 3 / 2$ and $\mathrm{Sn} 3 \mathrm{~d} 5 / 2$ peaks. The peak symmetry, the binding energies values, and the spin-orbit splitting $(8.4 \mathrm{eV})$ fit well with that found in the literature and indicates that the tin is of pure tetravalent oxidation state $\left(\mathrm{Sn}^{4+}\right)$. [25] Oxygen atoms are about 48.0 atom\% and exist in the framework mainly as tin dioxide. [24] The presence of two type of oxygen (small amount of $\mathrm{OH}^{-}$around $531.6 \mathrm{eV}$ and a majority of $\mathrm{O}^{2-}$ around $530.6 \mathrm{eV}$ ) indicate that the surface layers consist of some hydroxide form and/or physisorbed water vapour. This hydroxide is less for the $500{ }^{\circ} \mathrm{C}$-calcined sample (see Fig. 8). 


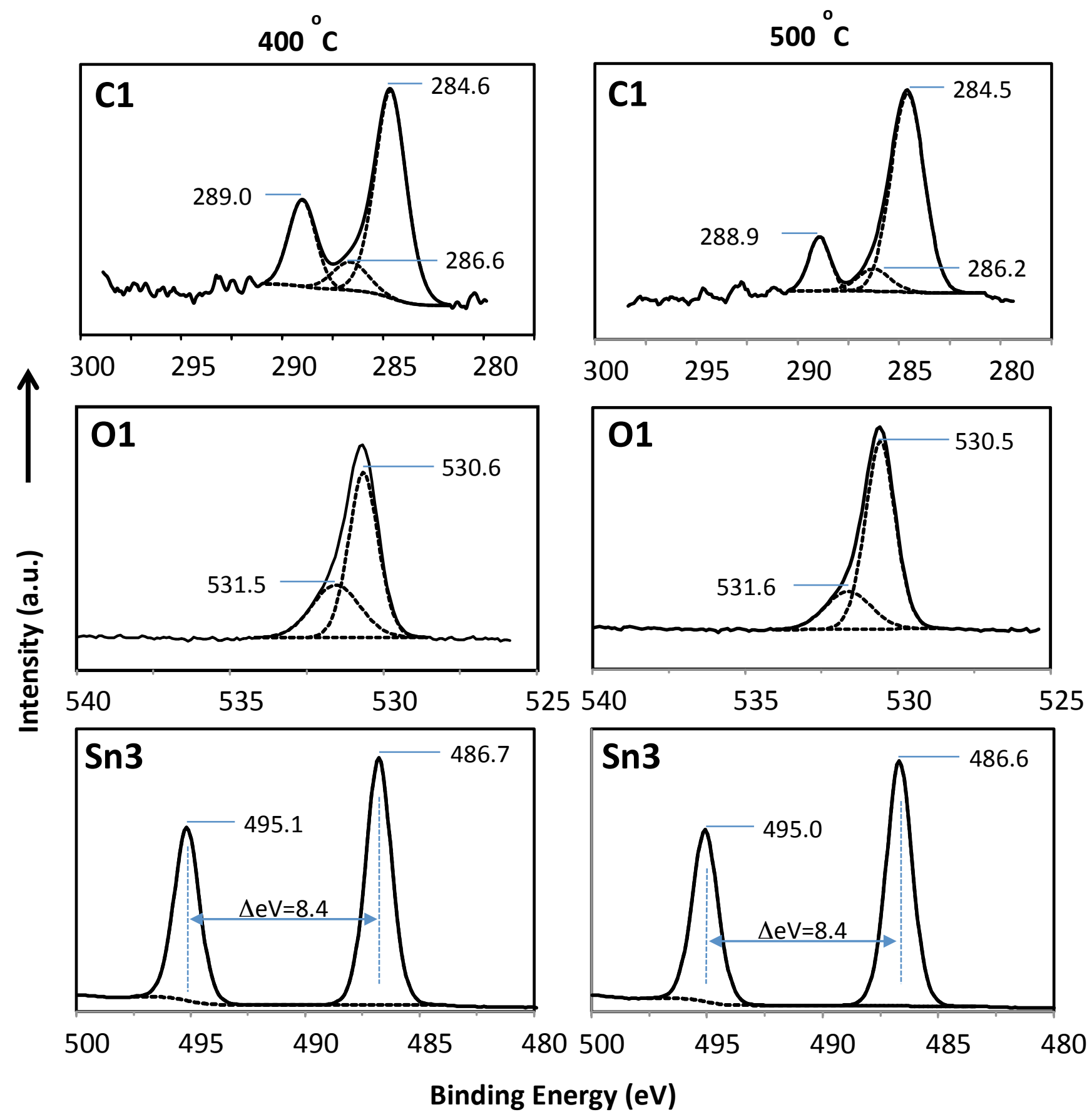

Figure 8 Deconvoluted C1s, O1s and Sn3d XPS spectrum. Sample calcined at $400{ }^{\circ} \mathrm{C}$ (left); sample calcined at $500^{\circ} \mathrm{C}$ (right). 
Table 1. XPS Elemental and Quantification for samples calcined at $400{ }^{\circ} \mathrm{C}$ and at $500{ }^{\circ} \mathrm{C}$

\begin{tabular}{cccccc}
\hline Peak (400 ${ }^{\circ} \mathrm{C}$ sample) & BE/eV & Intensity/Counts & FWHM/eV & Atom \% & $Q$ \\
\hline N1s & 400.36 & 74.22 & 2.1 & 0.26 & 1 \\
C1s & $* 284.63$ & 306.38 & 1.81 & 1.25 & 1 \\
C1s A & 289.01 & 127.67 & 1.58 & 0.44 & 1 \\
C1s B & 286.63 & 42.18 & 2.04 & 0.19 & 1 \\
Sn3d5 & 486.78 & 139750.08 & 1.29 & 24.95 & 1 \\
Sn3d3 & 495.18 & 97875.59 & 1.28 & 25.08 & 1 \\
O1s & 530.66 & 31326.88 & 1.12 & 31.47 & 1 \\
O1sA & 531.56 & 10002.46 & 1.84 & 16.18 & 1 \\
\hline Peak (500 ${ }^{\circ}$ C sample) & & & & & \\
\hline N1s & 400.53 & 66.55 & 1.73 & 0.12 & 1 \\
C1s & $* 284.51$ & 396.97 & 1.91 & 1.21 & 1 \\
C1sA & 288.93 & 107.68 & 1.23 & 0.21 & 1 \\
C1sB & 286.26 & 44.53 & 1.88 & 0.14 & 1 \\
Sn3d5 & 486.68 & 190376.42 & 1.29 & 24.62 & 1 \\
Sn3d3 & 495.09 & 133297.92 & 1.28 & 24.71 & 1 \\
O1s & 530.57 & 50115.93 & 1.14 & 37.17 & 1 \\
O1sA & 531.63 & 10103.21 & 1.76 & 11.33 & 1 \\
\hline
\end{tabular}

*Binding Energy at $284.6 \mathrm{eV}$ represents adventitious carbon

\section{Conductivity results}

Conductivity measurements were carried out using two banana cables at room temperature. It was not possible to construct a device to measure conductivity at elevated temperature as every time the temperature was increased, the resistivity of the metallic wires connected between the sample and the probes increased and, as a result, the total conductivity of the system decreased. Readings taken at room temperature gave an average result of $54 \times 10^{-3} \mathrm{~S} \mathrm{~m}^{-1}$ for the sample calcined at 400 ${ }^{\circ} \mathrm{C}$ and $164 \times 10^{-3} \mathrm{~S} \mathrm{~m}^{-1}$ for the sample calcined at $500{ }^{\circ} \mathrm{C}$. Both samples confirm that the mesoporous tin dioxide classifies as a semiconductor and conductivity is predicted to increase with an increase in temperature.

\section{Conclusion}

Mesoporous tin dioxide powder has been prepared via a direct soft templating method which is highly reproducible. The porous structure is able to withstand calcination at $400{ }^{\circ} \mathrm{C}$ and $500{ }^{\circ} \mathrm{C}$ and shows high BET surface areas of 220 and $100 \mathrm{~m}^{2} \mathrm{~g}^{-1}$, respectively. The crystal and pore sizes increase as a result of increasing the temperature during the calcination step, explaining why an increased 
dwell time is essential to control the sample morphology and prevent total collapse of the structure into a dense oxide of low surface area.

\section{EXPERIMENTAL}

\section{Characterisation}

X-ray diffraction performed using Bruker AXS D8 advanced diffractometer, using a copper target $(\lambda=$ $1.5418 \AA$ ) and DIFFRAC ${ }^{\text {plus }}$ software. The surface areas of the calcined samples were determined by BET adsorption-desorption measurement on a Micrometrics Tristar analyser, using nitrogen as the adsorbing gas. Transmission electron microscopic (TEM) images were attained using a JEOL JEM2011 electron microscope operated at 200 kV. The TEM images were recorded using a Gatan 794 CCD camera. This electron microscope is equipped with an Oxford Link ISIS SemiSTEM EDX system, which was used for confirming the chemical compositions at University of St Andrews. Conductivity measurements were performed using Agilent B2901A Source/Measure Unit (SMU) and two banana probes at $4 \mathrm{~mm}$ distance a part $42 \mathrm{~V}, 102 \mathrm{~mA}$ at room temperature. The X-ray photoelectron spectroscopy (XPS) spectra were recorded on a model Thermo ESCALAB 250Xi spectrometer using a monochromator with Al Ka radiation (1486.6 eV). The spectra acquisition and processing were carried out by means of Avantage data system. Sample was carefully introduced into the preparation chamber with the sample holder. It is then degassed until a good vacuum is achieved, then it was transferred into the analysis chamber. The analyses were carried out with the parameters: Analysis chamber pressure 10 -9 Torr, step size $0.1 \mathrm{eV}$, dwell time $100 \mathrm{~ms}$, and pass energy of $20 \mathrm{eV}$. All binding energy values were determined with respect to ${ }^{\circ} \mathrm{C} 1 \mathrm{~s}$ line $(284.6 \mathrm{eV})$ origination from adventitious carbon. Flood gun with standard charge compensation mode was used to neutralize the charge build up on the surface of insulating samples.

\section{Preparation}

Mesoporous $\mathrm{SnO}_{2}$ was prepared by slow stirring hexadecylamine $(0.26 \mathrm{~g})$ mixed in ' $\mathrm{PrOH}\left(24.4 \mathrm{~cm}^{3}\right)$ until dissolving completely then $\mathrm{Sn}\left(\mathrm{O}^{\mathrm{i}} \mathrm{Pr}\right)_{4}(1.9 \mathrm{~g})$ added at room temperature giving molar ratio of 0.2: 60:1 respectively. The reaction left under water-saturated air (about $80 \%$ humidity) for three days, the product was filtered and washed with water and then ethanol. Then transferred to Soxhlet extraction using ethanol, as a solvent, left over night (about $16 \mathrm{~h}$ ) to remove the surfactant then filtered. The product was calcined at temperature of $300^{\circ} \mathrm{C}, 400{ }^{\circ} \mathrm{C}$ and $500^{\circ} \mathrm{C}$ in air (heating rate 2 ${ }^{\circ} \mathrm{C} \mathrm{min}^{-1}$ ) for periods mentioned in the text.

All Chemicals where used as purchased from Alfa Aesarand used with good chemical practices. 


\section{Acknowledgment}

This project is supported by PAAET project no. BE-13-08 in collaboration with Kuwait University and the University of York. The support of the research administration of Kuwait University to the XPS instrument (Project No. GS02/08) is acknowledged.

\section{References}

1- Y. Wang, I. Ramos, J. J. Santiago-Aviles, J. Appl. Phys., 2007, 102, 093517.

2- A. Eberheim, D. Kohl and P. Schieberle, Phys. Chem. Chem. Phys., 2003, 5, 5203-5206.

3- G. Gaggiotti, A. Galdikas, S. Kaciulis, G. Mattogno, A. Setkus, J. Appl. Phys., 1994, Vol. 76, 8, 15.

4- V. A. Moshnikov, I. E. Gracheva, and M. G. An'chkov, Glass Phys. Chem., 2011, 37, 485.

5- C. J. Martinez, B. Hockey, C. B. Montgomery, S. Semancik, Langmuir 2005, 21, 7937.

6- Y. Zhang, Y. Liu, and M. Liu, Chem. Mater., 2006, 18, 4643.

7- A.H. Whitehead, J.M. Elliott, J.R. Owen, J. Power Sources, 1999, 81-82, 33.

8- Md. T. Uddin, Y. Nicolas, C. Olivier, T. Toupance, L. Servant, M. M. Müller, H.-J. Kleebe, J. Ziegler, and W. Jaegermann, Inorg. Chem., 2012, 51, 7764.

9- P. Zhu, M. V. Reddy, Y. Wu, S. Peng, S. Yang, A. S. Nair, K. P. Loh, B. V. R. Chowdari, S. Ramakrishna, J. Mater. Chem., 2008, 18, 771.

10- J. H. Pan, S. Y. Chai, C. Lee, S.-E. Park, W. I. Lee, J. Phys. Chem. C, 2007, 111, 5582.

11- V. N. Urade and H. W. Hillhouse, J. Phys. Chem. B, 2005, 109, 10538.

12- Y. Aksu, S. Frasca, U. Wollenberger, M. Driess, and A. Thomas, Chem. Mater., 2011, 23, 1798.

13- F. A. Garcés , L. N. Acquaroli, R. Urteaga, A. Dussan, R. R. Koropecki and R.D. Arce, Thin Solid Films, 2012, 520, 4254.

14- H. Kim, J. Cho, J. Mater. Chem., 2008, 18, 771.

15- J. K. Shon, S. S. Kong, Y. S. Kim, J.-H. Lee, W. K. Park, S. C. Park, J. M. Kim, Micropor. Mesopor. Mat., 2009, 120, 441.

16- D. Chandra, N. Mukherjee, A. Mondal, and A. Bhaumik, J. Phys. Chem. C, 2008, 112, 8668.

17- K. G. Severin, T. M. Abdel-Fattah and T. J. Pinnavaia, Chem. Commun., 1998, 1471. 
18- X. Wang, S. S. Yee, W. P. Carey, Sensors and Actuators, B 24-25-1995,454-457

19- A. Dieguez, A. Romano-Rodringuez, J.R. Morante, U. Weimar, Sens. Actuators B, 1996, 31, 1.

20- D. P. Tunstall, S. Patou, R. S. Liu, and Y. H. Kao, Mat. Res. Bull., 1999, 34, 1513.

21- K. S. W. Sing, D. H. Everett, R. A. W. Haul, L. Mouscou, R. A. Pierottin, J. Rouquerol and T. Siemieniewska, 1985, Pure Appl. Chem., 1985, 57, 603.

22- Wenbo. B. Yue, Wuzong Z. Zhou, Prog. Natural Sci., 18, 1329, 2008.

23- Xianfeng Yang, Junxiang Fu, Chongiun Jin, Jian Chen, Chaolun Liang, Mingmei Wu, Wuzong Zhou, J. Am. Chem. Soc., 2010, 132, 40, pp 14279-14287.

24- The XPS data were interpreted based on the following website and the references contained therein: http://lasurface.com/database/elementxps.php.

25- Soumen Das, Dae-Young Kim, Cheol-Min Choi, Yoon-Bong Hahn, Materials Research Bulletin, 46 (2011) 609-614. 